\title{
Salt effect on the (polyethylene glycol $8000+$ sodium sulfate) aqueous two-phase system: Relative hydrophobicity of the equilibrium phases
}

\author{
Luisa A. Ferreira*, José A. Teixeira \\ IBB - Institute for Biotechnology and Bioengineering, Centre for Biological Engineering, Universidade do Minho, Campus de Gualtar, 4710-057 Braga, Portugal
}

\section{A R T I C L E I N F O}

\section{Article history:}

Received 3 January 2011

Received in revised form 3 March 2011

Accepted 18 March 2011

Available online 23 March 2011

\section{Keywords:}

Aqueous two-phase systems

Salt effect

Relative hydrophobicity

Gibbs free energy of transfer

\begin{abstract}
A B S T R A C T
The relative hydrophobicity of the phases of several \{polyethylene glycol (PEG) 8000 + sodium sulfate $\left(\mathrm{Na}_{2} \mathrm{SO}_{4}\right)$ ) aqueous two-phase systems (ATPSs), all containing $0.01 \mathrm{~mol} \cdot \mathrm{L}^{-1}$ sodium phosphate buffer (NaPB, pH 7.4) and increasing concentration of a salt additive, $\mathrm{NaCl}$ or $\mathrm{KCl}$, up to $1.0 \mathrm{~mol} \cdot \mathrm{L}^{-1}$, was measured by the free energy of transfer of a methylene group between the phases, $\Delta G\left(\mathrm{CH}_{2}\right)$. The $\Delta G\left(\mathrm{CH}_{2}\right)$ of the systems was determined by partitioning of a homologous series of five sodium salts of dinitrophenylated (DNP) - amino acids with aliphatic side chains in three different tie-lines of each biphasic system. The relative hydrophobicity of the phases ranged from -0.125 to $-0.183 \mathrm{kcal} \cdot \mathrm{mol}^{-1}$, being the $\mathrm{NaCl}$ salt the one to provide the more effective changes. The results show that, within each system, there is a linear relationship between the $\Delta G\left(\mathrm{CH}_{2}\right)$ and the tie-line length (TLL), and biphasic systems with high salt additive concentration present the most negative $\Delta G\left(\mathrm{CH}_{2}\right)$ values. Therefore, the feasibility of establishing a relationship between the relative hydrophobicity of the phases in a given TLL and the ionic strength of the salt additive was investigated and a satisfactory correlation was found for each salt.
\end{abstract}

(c) 2011 Elsevier Ltd. All rights reserved.

\section{Introduction}

Liquid-liquid extraction using aqueous two-phase systems (ATPSs) has proved to be a promising separation strategy for many biological products [1-5]. To a large extent, interest in the partitioning behavior of proteins and other biomolecules in ATPSs have been stimulated by the potential of these systems to provide innocuous environments for the treatment of biological materials [1-6]. It is an environmentally friendly and easy to scale-up technology and it does not require the use of expensive equipment. A conventional ATPS is a biphasic system composed of a water solution containing a specific concentration of two hydrophilic polymers or one hydrophilic polymer and one salt [7,8]. The distribution of the solute between the two aqueous solution phases is characterized by the partition coefficient $(K)$ defined as ratio of the solute concentration between the top and bottom phases.

The physicochemical mechanisms underlying the partitioning of molecules in an ATPS are very complex because of the involvement of several factors in the interactions between the solute and the phase-forming components [9]. The type, molecular weight and concentration of phase forming polymers, type and concentration of phase-forming salt, type and concentration of salt additives, $\mathrm{pH}$ and temperature are parameters of extreme importance.

\footnotetext{
* Corresponding author. Tel.: +351 253604420; fax: +351 253678986 .

E-mail address: laferreira@deb.uminho.pt (L.A. Ferreira).
}

The salting-out ability of the salt-rich phase and the exclusion limit of the polymer-rich phase are the main factors to determine the partition of biological macromolecules in PEG-salt systems [10]. Salts are often used in polymer/salt ATPS to direct partitioning of target molecules between phases [7,11]. Previous studies have shown that the addition of a neutral salt such as $\mathrm{NaCl}$ can strongly affect the extraction performance parameters [5,9,11-13], being this effect attributed to possible hydrophobic interactions.

A scale of hydrophobicity based on the free energy of transfer of a methylene group between the phases, $\Delta G\left(\mathrm{CH}_{2}\right)$, proposed by Zaslavsky and coworkers [8,14], has been used to estimate the relative hydrophobicity of several ATPSs [4,15-19]. ATPSs appear as a practical alternative to the 1-octanol/water biphasic system for the determination of hydrophobicity used in the correlation of drug action in Quantitative Structure-Activity Relationships (QSAR). Moreover, a Linear Solvation Energy Relationship (LSER), recently reported to be applicable to partitioning of solutes in ATPSs [20-22], have used $\Delta G\left(\mathrm{CH}_{2}\right)$ as a molecular descriptor for the characterization of the solvent properties of the phases of a given system.

In this work we have studied the influence of salt additive $(\mathrm{NaCl}$ or $\mathrm{KCl}$ ) composition on the hydrophobic character of the coexisting phases in ATPSs composed of polyethylene glycol-8000 (PEG 8000) and sodium sulfate $\left(\mathrm{Na}_{2} \mathrm{SO}_{4}\right)$, containing a fixed concentration of $0.01 \mathrm{~mol} \cdot \mathrm{L}^{-1}$ sodium phosphate buffer (NaPB), $\mathrm{pH} 7.4$, and salt additive increasing concentration up to $1 \mathrm{~mol} \cdot \mathrm{L}^{-1}$. Partitioning behavior of homologous series of five sodium salts of 
dinitrophenylated (DNP-) amino acids with aliphatic side chains, in the absence and presence of salt additive, in three different tie lines of each biphasic systems, were measured and $\Delta G\left(\mathrm{CH}_{2}\right)$ determined.

\section{Experimental}

\subsection{Material}

Polyethylene glycol (PEG) 8000 (batch\# 059H0121), with average molecular weight $\left(M_{\mathrm{w}}\right)$ of 8000 , was supplied by Sigma-Aldrich. Sodium sulfate $\left(\mathrm{Na}_{2} \mathrm{SO}_{4}\right.$; anhydrous, GR for analysis, ACS, Reag. Ph Eur), sodium dihydrogen phosphate dihydrate $\left(\mathrm{NaH}_{2} \mathrm{PO}_{4} \cdot 2 \mathrm{H}_{2} \mathrm{O}\right.$; p.a., Reag. Ph Eur), and disodium hydrogen phosphate $\left(\mathrm{Na}_{2} \mathrm{HPO}_{4}\right.$; anhydrous, GR for analysis, ACS, Reag. Ph Eur) were purchased from Merck. Sodium chloride ( $\mathrm{NaCl})$, extra pure, was provided by Acros Organics and potassium chloride $(\mathrm{KCl})$ was obtained from Panreac (purity $\geqslant 0.995$ ). Stock solutions of each chemical were prepared in deionized water and the concentrations were obtained after lyophilization (ca. $50 \%$ by weight for PEG 8000 and $17 \%$ by weight for $\mathrm{Na}_{2} \mathrm{SO}_{4}$ ). Sodium phosphate buffer (NaPB, $0.2 \mathrm{~mol} \cdot \mathrm{L}^{-1}, \mathrm{pH} 7.4$ ) was prepared combining the $\mathrm{Na}_{2} \mathrm{HPO}_{4}$ and $\mathrm{NaH}_{2} \mathrm{PO}_{4} \cdot 2 \mathrm{H}_{2} \mathrm{O}$ salts. The $\mathrm{pH}$ value was confirmed using a $\mathrm{pH}$ meter (CRISON, microTT 2050, Spain). Stock solutions of $5 \mathrm{~mol} \cdot \mathrm{L}^{-1} \mathrm{NaCl}$ and $3 \mathrm{~mol} \cdot \mathrm{L}^{-1} \mathrm{KCl}$ were used. Dinitrophenylated (DNP)-amino acids were purchased from Sigma: n-(2,4-dinitrophenyl)-glycine (DNP-Gly), n-(2,4-dinitrophenyl)-L-alanine (DNP-Ala), n-(2,4-dinitrophenyl)-DL-norvaline (DNP-NVal), n-(2,4-dinitrophenyl)-DL-norleucine (DNP-NLeu), n-(2,4-dinitrophenyl)-DL- $\alpha$-amino-n-caprylic acid (DNP-AO). DNP- amino acids solutions of $10 \mathrm{mmol} \cdot \mathrm{L}^{-1}$ were prepared in $10 \mathrm{mmol} \cdot \mathrm{L}^{-1} \mathrm{NaOH}$ and the exposure to light minimized. All products were used as received without further purification. Deionized water was used for all diluting purposes. All weighing was carried out on an analytical balance precise to within $\pm 0.2 \mathrm{mg}$ (OHAUS, Explorer Pro, model EP214DC, Switzerland).

\subsection{Methods}

The systems were prepared by weighing the appropriated amounts of PEG 8000 and $\mathrm{Na}_{2} \mathrm{SO}_{4}$ stock solutions. Appropriated amounts of buffer solution and the required salt concentration were added to the systems, in order to achieve the desired composition. Different (PEG $8000+\mathrm{Na}_{2} \mathrm{SO}_{4}$ ) ATPSs, all containing $0.01 \mathrm{~mol} \cdot \mathrm{L}^{-1} \mathrm{NaPB}, \mathrm{pH} 7.4$, and concentration of a neutral salt such as $\mathrm{NaCl}$ or $\mathrm{KCl}$, increased up to $1.0 \mathrm{~mol} \cdot \mathrm{L}^{-1}$, were prepared with a final total weight (after addition of sample solution) of $0.5 \mathrm{~g}$.

Partition coefficients of five DNP-amino acids were measured in three different tie-lines of a set of ATPSs previously reported [23]. The feed compositions of the tie-lines used for partitioning experiments are listed in table 1 . The DNP-amino acid stock solution was added into each ATPS at six different concentrations (0 to $100 \mathrm{mg}$ ) and the corresponding amount of water (100 to $0 \mathrm{mg}$ ) for a final system weight of ca. $0.5 \mathrm{~g}$. Systems were vortex-mixed and centrifuged for $30 \mathrm{~min}$ at $3000 \mathrm{~g}$ (HERMLE, Z36HK, Germany) to accelerate phase separation. After, samples of each phase were withdrawn and conveniently diluted. Following vortexing, $300 \mu \mathrm{L}$ aliquots were transferred into microplate wells, and the UV-Vis spectrophotometer (ELISA reader, Biotech, Synergy HT, USA) used to mea-

TABLE 1

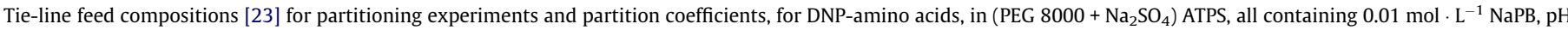
7.4, and increasing concentration of a neutral salt [salt], $\mathrm{NaCl}$ or $\mathrm{KCl}$, up to $1.0 \mathrm{~mol} \cdot \mathrm{L}^{-1}(296.15 \mathrm{~K})$.

\begin{tabular}{|c|c|c|c|c|c|c|c|c|c|}
\hline \multirow[t]{2}{*}[\text{Salt}]{$/\left(\mathrm{mol} \cdot \mathrm{L}^{-1}\right)$} & \multirow[t]{2}{*}{ Tie-line } & \multicolumn{2}{|c|}{ Composition $100 \mathrm{w}$} & \multirow[t]{2}{*}{ TLL } & \multirow[t]{2}{*}{ DNP-Gly } & \multirow[t]{2}{*}{ DNP-Ala } & \multirow[t]{2}{*}{ DNP-NVal } & \multirow[t]{2}{*}{ DNP-NLeu } & \multirow[t]{2}{*}{ DNP-AO } \\
\hline & & PEG 8000 & $\mathrm{Na}_{2} \mathrm{SO}_{4}$ & & & & & & \\
\hline \multicolumn{10}{|c|}{$\left(\right.$ PEG $8000+\mathrm{Na}_{2} \mathrm{SO}_{4}+$ water $)$} \\
\hline \multirow[t]{3}{*}{0.00} & 1 & 11.53 & 6.30 & 18.22 & $3.138 \pm 0.040$ & $3.566 \pm 0.015$ & $4.620 \pm 0.055$ & $5.743 \pm 0.073$ & $10.508 \pm 0.286$ \\
\hline & 2 & 11.97 & 6.60 & 20.96 & $4.618 \pm 0.066$ & $5.439 \pm 0.049$ & $7.299 \pm 0.116$ & $9.920 \pm 0.111$ & $18.716 \pm 0.264$ \\
\hline & 3 & 12.56 & 6.90 & 24.68 & $5.571 \pm 0.033$ & $6.570 \pm 0.063$ & $9.688 \pm 0.119$ & $12.816 \pm 0.196$ & $26.889 \pm 0.389$ \\
\hline \multicolumn{10}{|c|}{$\left(\mathrm{PEG} 8000+\mathrm{Na}_{2} \mathrm{SO}_{4}+\mathrm{NaCl}+\right.$ water $)$} \\
\hline \multirow[t]{3}{*}{0.25} & 1 & 10.97 & 5.69 & 18.61 & $2.847 \pm 0.020$ & $3.289 \pm 0.030$ & $4.308 \pm 0.046$ & $5.349 \pm 0.061$ & $9.736 \pm 0.175$ \\
\hline & 2 & 11.56 & 5.89 & 21.30 & $3.384 \pm 0.029$ & $3.904 \pm 0.049$ & $5.089 \pm 0.080$ & $6.422 \pm 0.137$ & $12.658 \pm 0.274$ \\
\hline & 3 & 11.95 & 6.10 & 23.98 & $3.743 \pm 0.019$ & $4.271 \pm 0.033$ & $6.287 \pm 0.079$ & $8.009 \pm 0.065$ & $16.052 \pm 0.158$ \\
\hline \multirow[t]{3}{*}{0.50} & 1 & 10.09 & 5.49 & 18.01 & $2.608 \pm 0.039$ & $2.996 \pm 0.030$ & $3.924 \pm 0.069$ & $4.912 \pm 0.031$ & $8.737 \pm 0.120$ \\
\hline & 2 & 10.50 & 5.69 & 20.22 & $2.596 \pm 0.013$ & $3.159 \pm 0.046$ & $4.291 \pm 0.070$ & $5.325 \pm 0.080$ & $11.031 \pm 0.508$ \\
\hline & 3 & 11.03 & 5.89 & 22.58 & $3.120 \pm 0.037$ & $3.686 \pm 0.018$ & $5.273 \pm 0.036$ & $6.638 \pm 0.061$ & $13.110 \pm 0.269$ \\
\hline \multirow[t]{3}{*}{0.75} & 1 & 10.50 & 5.50 & 20.44 & $2.750 \pm 0.022$ & $3.117 \pm 0.024$ & $4.445 \pm 0.037$ & $5.681 \pm 0.047$ & $11.125 \pm 0.127$ \\
\hline & 2 & 10.99 & 5.70 & 22.76 & $3.037 \pm 0.017$ & $3.625 \pm 0.039$ & $5.145 \pm 0.042$ & $6.622 \pm 0.078$ & $15.016 \pm 0.190$ \\
\hline & 3 & 11.57 & 5.89 & 25.03 & $3.444 \pm 0.043$ & $4.329 \pm 0.039$ & $6.235 \pm 0.036$ & $8.551 \pm 0.067$ & $17.970 \pm 0.076$ \\
\hline \multirow[t]{3}{*}{1.00} & 1 & 9.50 & 5.29 & 17.87 & $2.522 \pm 0.025$ & $3.030 \pm 0.017$ & $4.419 \pm 0.047$ & $5.809 \pm 0.087$ & $11.234 \pm 0.151$ \\
\hline & 2 & 10.03 & 5.50 & 20.64 & $2.658 \pm 0.030$ & $3.194 \pm 0.021$ & $4.912 \pm 0.043$ & $6.579 \pm 0.042$ & $14.577 \pm 0.513$ \\
\hline & 3 & 10.52 & 5.69 & 23.23 & $2.869 \pm 0.048$ & $3.476 \pm 0.026$ & $5.355 \pm 0.074$ & $7.208 \pm 0.128$ & $16.961 \pm 0.377$ \\
\hline \multicolumn{10}{|c|}{$\left(\right.$ PEG $8000+\mathrm{Na}_{2} \mathrm{SO}_{4}+\mathrm{KCl}+$ Water $)$} \\
\hline \multirow[t]{3}{*}{0.25} & 1 & 11.03 & 5.71 & 18.26 & $2.795 \pm 0.066$ & $3.336 \pm 0.038$ & $4.376 \pm 0.072$ & $5.594 \pm 0.0282$ & $9.871 \pm 0.176$ \\
\hline & 2 & 11.49 & 5.91 & 20.47 & $3.234 \pm 0.036$ & $3.714 \pm 0.051$ & $5.098 \pm 0.021$ & $6.630 \pm 0.096$ & $11.517 \pm 0.267$ \\
\hline & 3 & 12.04 & 11.49 & 23.21 & $3.737 \pm 0.037$ & $4.349 \pm 0.033$ & $5.932 \pm 0.077$ & $7.563 \pm 0.035$ & $15.574 \pm 0.254$ \\
\hline \multirow[t]{3}{*}{0.50} & 1 & 10.01 & 5.52 & 16.59 & $2.478 \pm 0.033$ & $2.900 \pm 0.044$ & $3.807 \pm 0.026$ & $4.749 \pm 0.021$ & $8.973 \pm 0.186$ \\
\hline & 2 & 10.47 & 5.71 & 19.61 & $2.885 \pm 0.031$ & $3.298 \pm 0.033$ & $4.553 \pm 0.066$ & $5.828 \pm 0.040$ & $10.950 \pm 0.109$ \\
\hline & 3 & 11.03 & 5.90 & 22.30 & $3.097 \pm 0.033$ & $3.681 \pm 0.046$ & $5.200 \pm 0.067$ & $6.923 \pm 0.077$ & $13.731 \pm 0.331$ \\
\hline \multirow[t]{3}{*}{0.75} & 1 & 10.00 & 5.30 & 17.38 & $2.558 \pm 0.037$ & $2.822 \pm 0.018$ & $3.809 \pm 0.027$ & $4.908 \pm 0.048$ & $9.950 \pm 0.207$ \\
\hline & 2 & 10.50 & 5.51 & 20.57 & $2.654 \pm 0.048$ & $3.180 \pm 0.023$ & $4.400 \pm 0.008$ & $5.975 \pm 0.071$ & $12.412 \pm 0.167$ \\
\hline & 3 & 11.07 & 5.71 & 22.85 & $3.055 \pm 0.008$ & $3.588 \pm 0.052$ & $5.169 \pm 0.041$ & $7.187 \pm 0.097$ & $15.255 \pm 0.158$ \\
\hline \multirow[t]{3}{*}{1.00} & 1 & 9.52 & 5.30 & 18.78 & $2.500 \pm 0.034$ & $3.103 \pm 0.013$ & $4.344 \pm 0.023$ & $5.711 \pm 0.057$ & $11.633 \pm 0.135$ \\
\hline & 2 & 10.00 & 5.52 & 21.20 & $2.660 \pm 0.021$ & $3.289 \pm 0.028$ & $4.791 \pm 0.069$ & $6.584 \pm 0.106$ & $13.747 \pm 0.122$ \\
\hline & 3 & 10.51 & 5.70 & 23.76 & $2.928 \pm 0.044$ & $3.657 \pm 0.052$ & $5.295 \pm 0.052$ & $7.266 \pm 0.038$ & $16.108 \pm 0.194$ \\
\hline
\end{tabular}




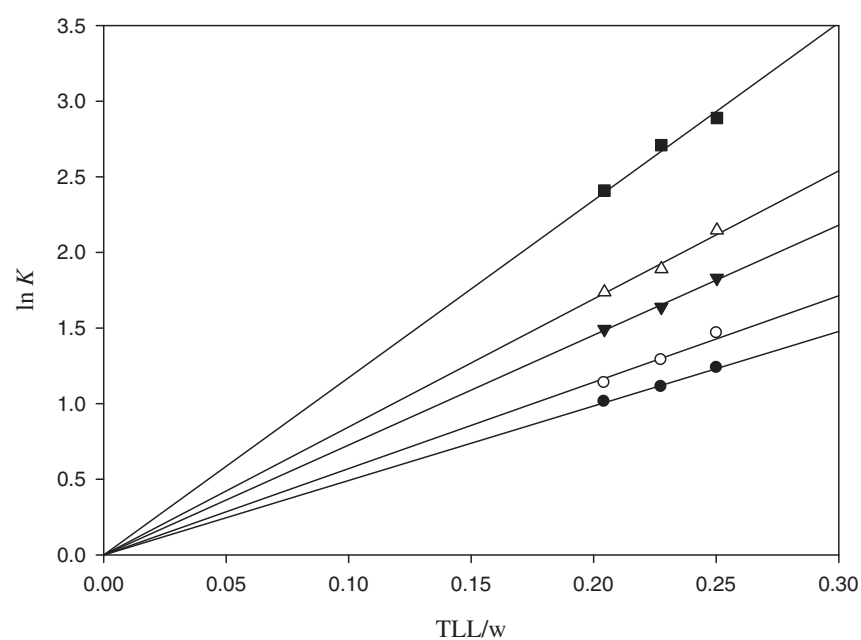

FIGURE 1. Logarithms of distribution coefficients of the DNP-amino acids ( $\ln K$ ) in a $\left(\right.$ PEG $\left.8000+\mathrm{Na}_{2} \mathrm{SO}_{4}\right)-0.75 \mathrm{~mol} \cdot \mathrm{L}^{-1} \mathrm{NaCl}-0.01 \mathrm{~mol} \cdot \mathrm{L}^{-1} \mathrm{NaPB}, \mathrm{pH} 7.4$, ATPS as a function of the TLL: $(\bullet)$ DNP-Gly; $(\bigcirc)$ DNP-Ala; $(\boldsymbol{\nabla})$ DNP-NVal; $(\Delta)$ DNP-NLeu; DNP-AO.

sure optical absorbance at the wavelength of maximum absorption (362 nm). Since there was a considerable difference between the concentrations of the DNP-amino acids in one phase relative to the other phase, different dilution factors were used for the top and bottom phases. Blank systems at corresponding dilutions were measured for comparison. The latter procedure and its advantages over more common protocol, including several partition experiments of a solute at a single concentration, have been explained and discussed in detail elsewhere [8]. The $K$ for the DNP-amino

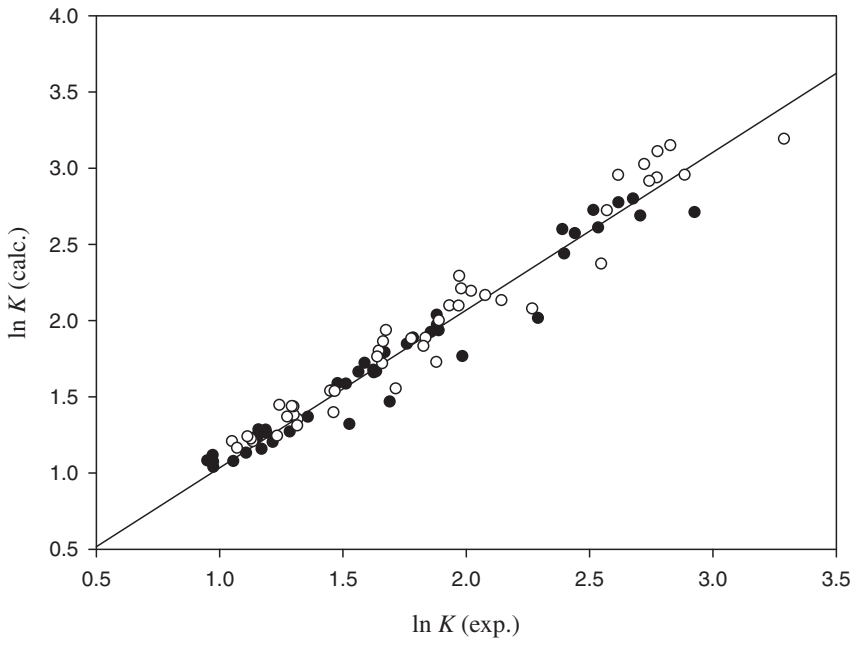

FIGURE 2. Comparison of experimental $\ln K$ data and calculated data based on equation (4): (O) Tie-line 2 (II) and Tie-line 1(I); $\bullet$ ) Tie-line 3 (II) and Tie-line 1(I) (see table 1 ).

acids, in a specific ATPS, was determined from the slope of the linear regression of the amino acid absorbance in the top phase plotted against that in the bottom phase, both corrected with the corresponding dilution factors $(D F)$ as given by $[4,8,17,18]$ :

$K=\left[A b s_{\text {top }} \cdot D F_{\text {top }}\right] /\left[A b s_{\text {bottom }} \cdot D F_{\text {bottom }}\right]$.

TABLE 2

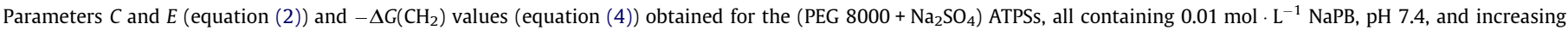
concentration of a neutral salt [salt], $\mathrm{NaCl}$ or $\mathrm{KCl}$, up to $1.0 \mathrm{~mol} \cdot \mathrm{L}^{-1}(296.15 \mathrm{~K})$.

\begin{tabular}{|c|c|c|c|c|c|}
\hline$[$ Salt $] /\left(\mathrm{mol} \cdot \mathrm{L}^{-1}\right)$ & Tie-line & $C$ & E & $r^{2}$ & $-\Delta G\left(\mathrm{CH}_{2}\right) /\left(\mathrm{kcal} \cdot \mathrm{mol}^{-1}\right)$ \\
\hline \multicolumn{6}{|c|}{$\left(\mathrm{PEG} 8000+\mathrm{Na}_{2} \mathrm{SO}_{4}+\right.$ water $)$} \\
\hline \multirow[t]{3}{*}{0.00} & 1 & $0.990 \pm 0.026$ & $0.212 \pm 0.007$ & 0.996 & 0.125 \\
\hline & 2 & $1.366 \pm 0.017$ & $0.247 \pm 0.005$ & 0.999 & 0.145 \\
\hline & 3 & $1.532 \pm 0.016$ & $0.277 \pm 0.004$ & 0.999 & 0.163 \\
\hline \multirow{4}{*}{0.25} & & (PEG 8 & $\mathrm{NaCl}+$ water $)$ & & \\
\hline & 1 & $0.902 \pm 0.019$ & $0.215 \pm 0.005$ & 0.998 & 0.126 \\
\hline & 2 & $1.048 \pm 0.037$ & $0.230 \pm 0.010$ & 0.994 & 0.136 \\
\hline & 3 & $1.141 \pm 0.022$ & $0.258 \pm 0.006$ & 0.998 & 0.152 \\
\hline \multirow[t]{3}{*}{0.50} & 1 & $0.817 \pm 0.014$ & $0.212 \pm 0.004$ & 0.999 & 0.125 \\
\hline & 2 & $0.798 \pm 0.034$ & $0.249 \pm 0.009$ & 0.996 & 0.147 \\
\hline & 3 & $0.981 \pm 0.017$ & $0.251 \pm 0.005$ & 0.999 & 0.148 \\
\hline \multirow[t]{3}{*}{0.75} & 1 & $0.834 \pm 0.021$ & $0.248 \pm 0.006$ & 0.998 & 0.146 \\
\hline & 2 & $0.913 \pm 0.038$ & $0.279 \pm 0.009$ & 0.995 & 0.164 \\
\hline & 3 & $1.072 \pm 0.009$ & $0.288 \pm 0.003$ & 0.999 & 0.169 \\
\hline \multirow[t]{3}{*}{1.00} & 1 & $0.773 \pm 0.010$ & $0.262 \pm 0.003$ & 0.999 & 0.154 \\
\hline & 2 & $0.784 \pm 0.016$ & $0.299 \pm 0.005$ & 0.999 & 0.176 \\
\hline & 3 & $0.846 \pm 0.023$ & $0.312 \pm 0.007$ & 0.999 & 0.183 \\
\hline \multirow{4}{*}{0.25} & & (PEG & $\mathrm{KCl}+$ water $)$ & & \\
\hline & 1 & $0.902 \pm 0.009$ & $0.220 \pm 0.002$ & 0.999 & 0.129 \\
\hline & 2 & $1.032 \pm 0.011$ & $0.225 \pm 0.003$ & 0.999 & 0.132 \\
\hline & 3 & $1.138 \pm 0.033$ & $0.250 \pm 0.009$ & 0.996 & 0.147 \\
\hline \multirow[t]{3}{*}{0.50} & 1 & $0.758 \pm 0.024$ & $0.224 \pm 0.007$ & 0.997 & 0.132 \\
\hline & 2 & $0.897 \pm 0.015$ & $0.236 \pm 0.004$ & 0.999 & 0.139 \\
\hline & 3 & $0.963 \pm 0.008$ & $0.262 \pm 0.002$ & 0.999 & 0.154 \\
\hline \multirow[t]{3}{*}{0.75} & 1 & $0.736 \pm 0.044$ & $0.241 \pm 0.012$ & 0.992 & 0.142 \\
\hline & 2 & $0.794 \pm 0.021$ & $0.271 \pm 0.006$ & 0.999 & 0.159 \\
\hline & 3 & $0.915 \pm 0.021$ & $0.285 \pm 0.006$ & 0.999 & 0.167 \\
\hline \multirow[t]{3}{*}{1.00} & 1 & $0.763 \pm 0.014$ & $0.267 \pm 0.004$ & 0.999 & 0.157 \\
\hline & 2 & $0.808 \pm 0.003$ & $0.288 \pm 0.001$ & 1.000 & 0.169 \\
\hline & 3 & $0.892 \pm 0.016$ & $0.297 \pm 0.004$ & 0.999 & 0.175 \\
\hline
\end{tabular}




\section{Results and discussion}

Recently, we have reported the effect of two salt additives $(\mathrm{NaCl}$ and $\mathrm{KCl}$ ), with concentration increasing up to $1.0 \mathrm{~mol} \cdot \mathrm{L}^{-1}$, on the ATPS formed by PEG 8000 and $\mathrm{Na}_{2} \mathrm{SO}_{4}$, containing a fixed concentration of $0.01 \mathrm{~mol} \cdot \mathrm{L}^{-1} \mathrm{NaPB}, \mathrm{pH} 7.4$ [23]. Phase diagrams were characterized by the binodal curve and tie-lines [23]. In this work, the $\Delta G\left(\mathrm{CH}_{2}\right)$ was been used to characterize the solvent features of the coexisting phases of those particular ATPS. According to this current approach, for any homologous series of solutes with varied aliphatic alkyl chain length, the distribution coefficient in a particular ATPS can be described as [8]:

$\ln K_{i}=C+E \cdot n\left(\mathrm{CH}_{2}\right)$,

where $\ln K_{i}$ is the natural logarithm of the distribution coefficient $K$, $n\left(\mathrm{CH}_{2}\right)$ is the length of the aliphatic chain of a given solute $i$ represented by the equivalent number of $\mathrm{CH}_{2}$ groups, $E$ is an average $\ln K_{i}$ increment per $\mathrm{CH}_{2}$ group; $\mathrm{C}$ represents the total contribution of the non-alkyl part of the structure of the solute in the series $\ln K_{i}$. The physical meaning of both parameters $C$ and $E$ was discussed in detail elsewhere $[4,8,17,18]$.

Table 1 lists the partition coefficients of the DNP-amino acids obtained in three different tie-lines of each biphasic systems with different salt additives and salt additive concentrations. In agreement with the previously reported for other ATPS [18,24], it was observed that there was a linear relation between the logarithms of the distribution coefficients and tie-line length (TLL) (figure 1). At the critical point ( $T L L=0$ ), both phases have the same composition and the partition coefficient becomes unity [4]. The results show that in all the systems, increasing of the TLL, the DNP-amino acids partition more preferentially to the upper (PEG-rich) phase. As exemplified in figure 1 , experimental data can be described as [18,24]:

$\ln K=\alpha \mathrm{TLL}$

being $\alpha$ a constant that characterizes the effect the composition of the equilibrium phases of a given system on the distribution coefficient $K$ of the solute in that system. Therefore, for a given system with different tie-lines (I and II), it results from equation (3) that:

$\ln K^{\mathrm{II}}=\left(\mathrm{TLL}^{\mathrm{II}} / \mathrm{TLL}^{\mathrm{I}}\right) \ln K^{\mathrm{I}}$.

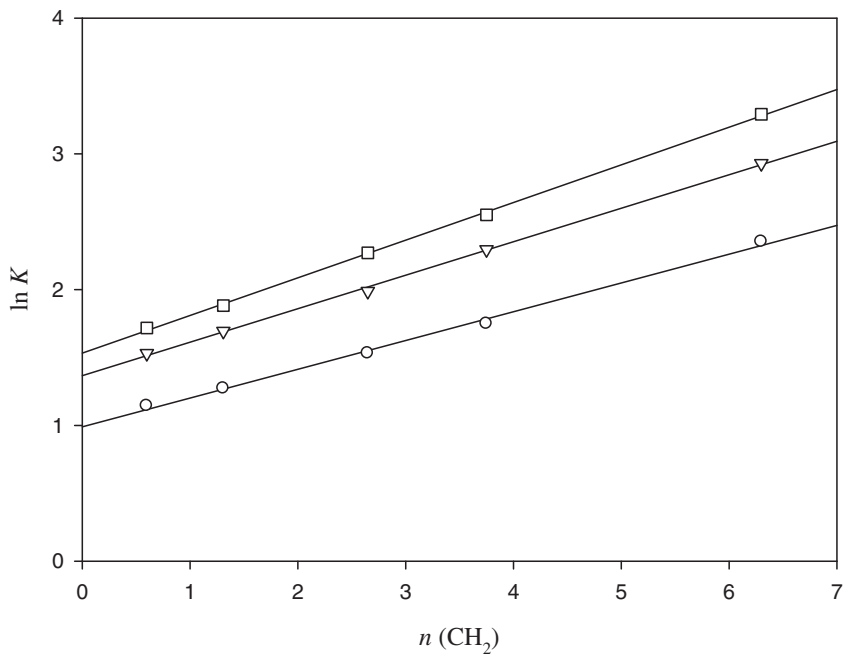

FIGURE 3. Logarithms of distribution coefficients of the DNP-amino acids ( $\ln K$ ) in a PEG $8000-\mathrm{Na}_{2} \mathrm{SO}_{4}-0.01 \mathrm{~mol} \cdot \mathrm{L}^{-1} \mathrm{NaPB}, \mathrm{pH} 7.4$, ATPS as a function of the average number of methylene group: Tie-line $1(\bigcirc), 2(\nabla)$, and $3(\square)$, respectively (see table 1).
In figure 2 , the calculated $\ln K$ (based on equation (4)) is plotted as a function of the experimental ln $K$ data and a good correlation was found being this relationship described as:

$$
\begin{aligned}
\ln K(\text { calc. }) & =(1.035 \pm 0.007) \ln K(\exp .), \quad N=90 ; r^{2} \\
& =0.956,
\end{aligned}
$$

where $N$ is the number of data points and $r^{2}$ is the correlation coefficient.

The parameters $E$ and $C$ (equation (2)) obtained by linear regression and the respective $r^{2}$ are given in table 2 . Figure 3 illustrates the relationship described by equation (2) for the DNP-amino acids in the ATPS without salt additive.

The Gibbs free energy of transfer $(\Delta G)$ of a component from one phase to another can be related with its partition coefficient as follows $[4,8,17,18]$ :

$\Delta G=-R T \ln K$

where $R$ is the universal gas constant and $T$ is the absolute temperature in Kelvin. It follows from equations (2) and (6) that the parameter $E$ may be used as a measure of the difference between the affinities of the two phases for a $\mathrm{CH}_{2}$ group, therefore, the relation with $\Delta G\left(\mathrm{CH}_{2}\right)$ can be described as:

$\Delta G\left(\mathrm{CH}_{2}\right)=-R T E$.
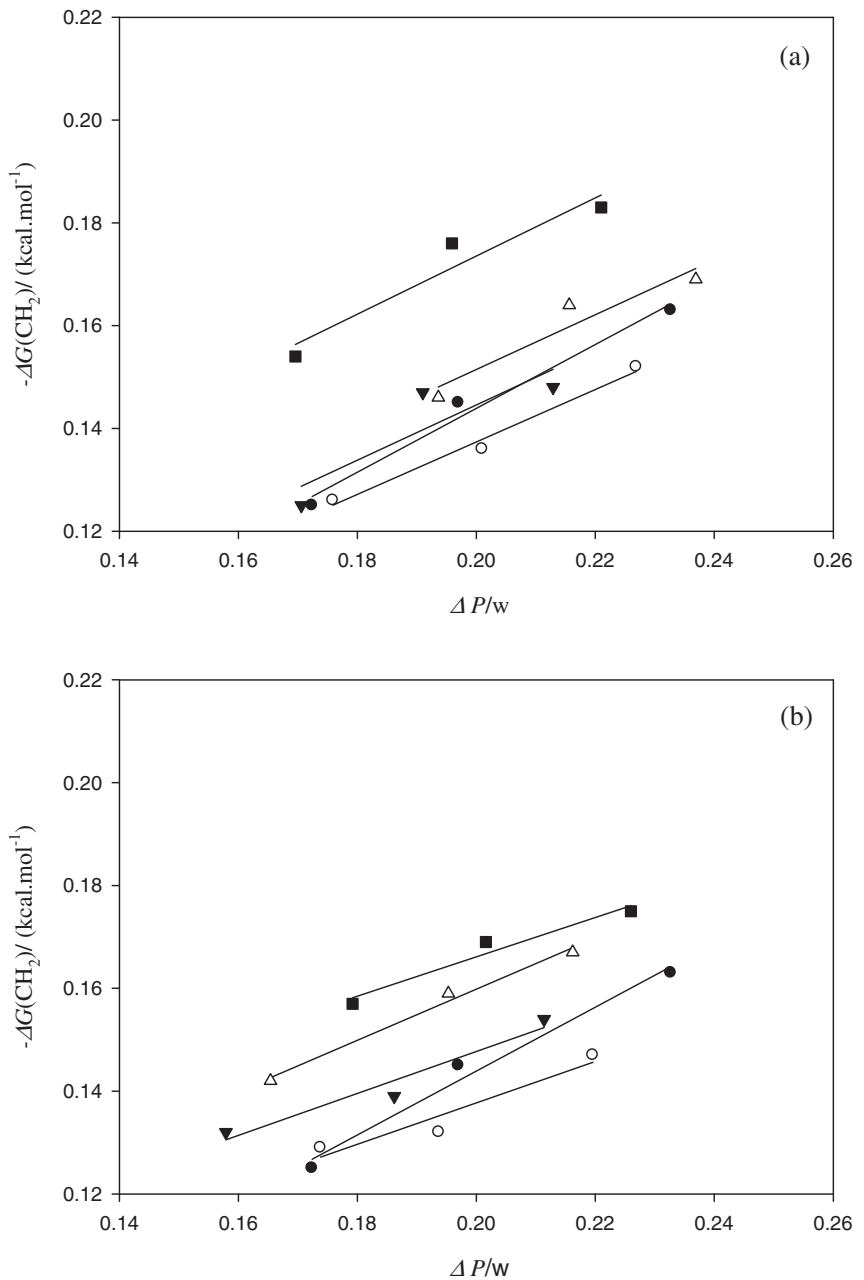

FIGURE 4. $\Delta G\left(\mathrm{CH}_{2}\right)$ values as a function of the $\Delta P$ [23] for ATPS studied: (a) $\mathrm{NaCl}$;

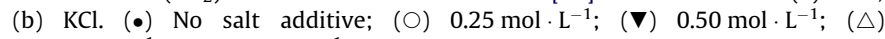
$0.75 \mathrm{~mol} \cdot \mathrm{L}^{-1} ;(\mathbf{\square}) 1.0 \mathrm{~mol} \cdot \mathrm{L}^{-1}$. 

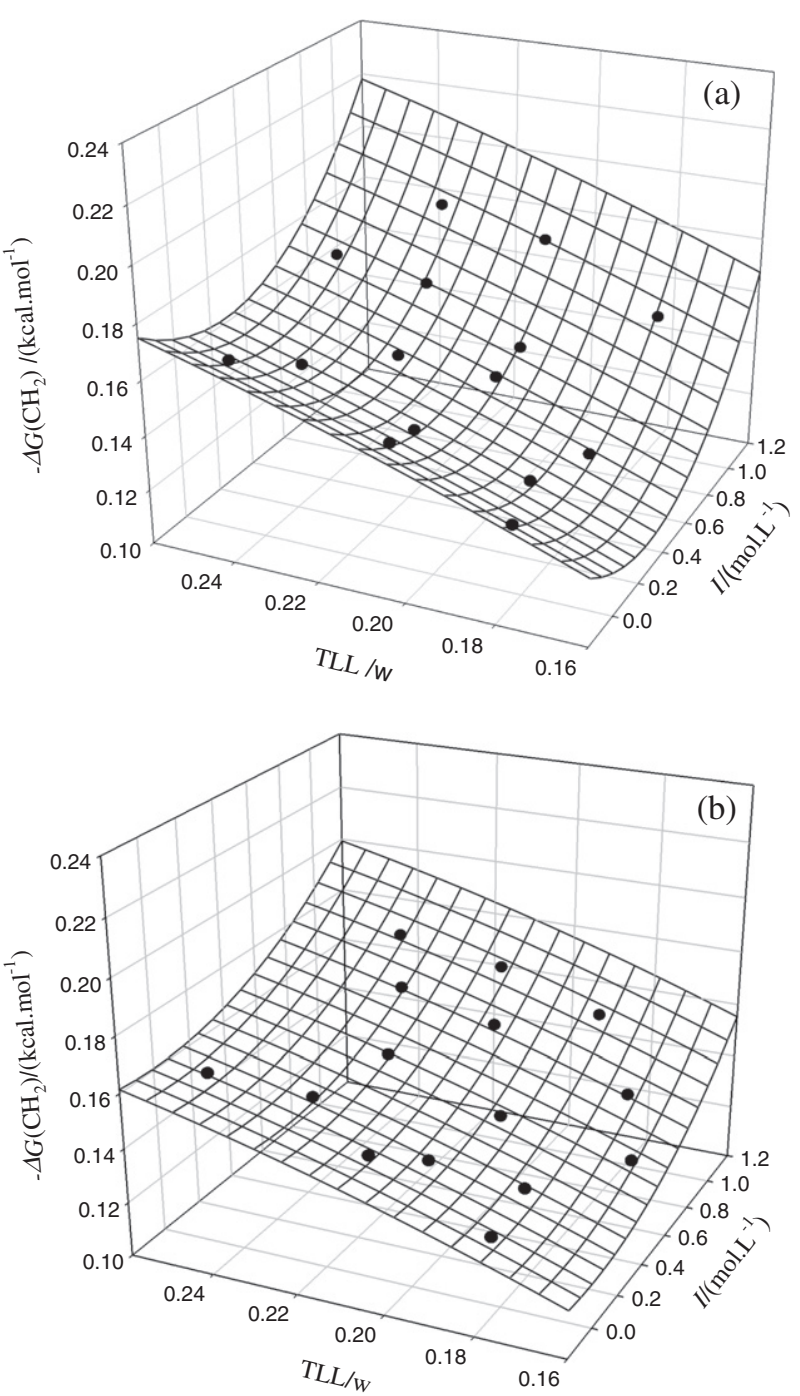

FIGURE 5. $\Delta G\left(\mathrm{CH}_{2}\right)$ values as a function of the TLL and ionic strength $(I)$ of the salt additive, 3D representation: (a) $\mathrm{NaCl}$; (b) $\mathrm{KCl}$.

The $\Delta G\left(\mathrm{CH}_{2}\right)$ values obtained from equation (7) and listed in table 2 are in agreement with others reported in the literature for different PEG-Salt ATPS without salt additives $[17,18,25]$. The negative $\Delta G\left(\mathrm{CH}_{2}\right)$ or the positive $E$ values obtained in the examined systems indicate that the PEG-rich phase (top phase) is more hydrophobic than the corresponding salt-rich phase (bottom) [8,17]. Figure 4 presents the $\Delta G\left(\mathrm{CH}_{2}\right)$ as a function of the difference in polymer composition between the equilibrium phases $(\Delta P)[23]$. The relative hydrophobicity is a parameter characteristic of each tie-line in a given ATPS and increases as the TLL increases, showing a linear trend. Experimental data for the system with no salt added is included in figure $4 a$ and $b$ in order to evaluate the effect of the increasing $\mathrm{NaCl}$ or $\mathrm{KCl}$ salt concentration. The results show that to promote considerable differences of hydrophobicity between the phases, when compared to the ATPS without salt addition, the concentration of added salt, either $\mathrm{NaCl}$ or $\mathrm{KCl}$, needs to be higher than $0.25 \mathrm{~mol} \cdot \mathrm{L}^{-1}$. Clearly the biphasic systems with high salt additive concentration present the most negative $\Delta G\left(\mathrm{CH}_{2}\right)$ values, suggesting a more efficient biphasic separation system [4]. It is noted that in a salt additive containing system the relative hydrophobicity of the phases can be adjusted over a significantly wide range by changing the total salt concentration and/or the TLL.
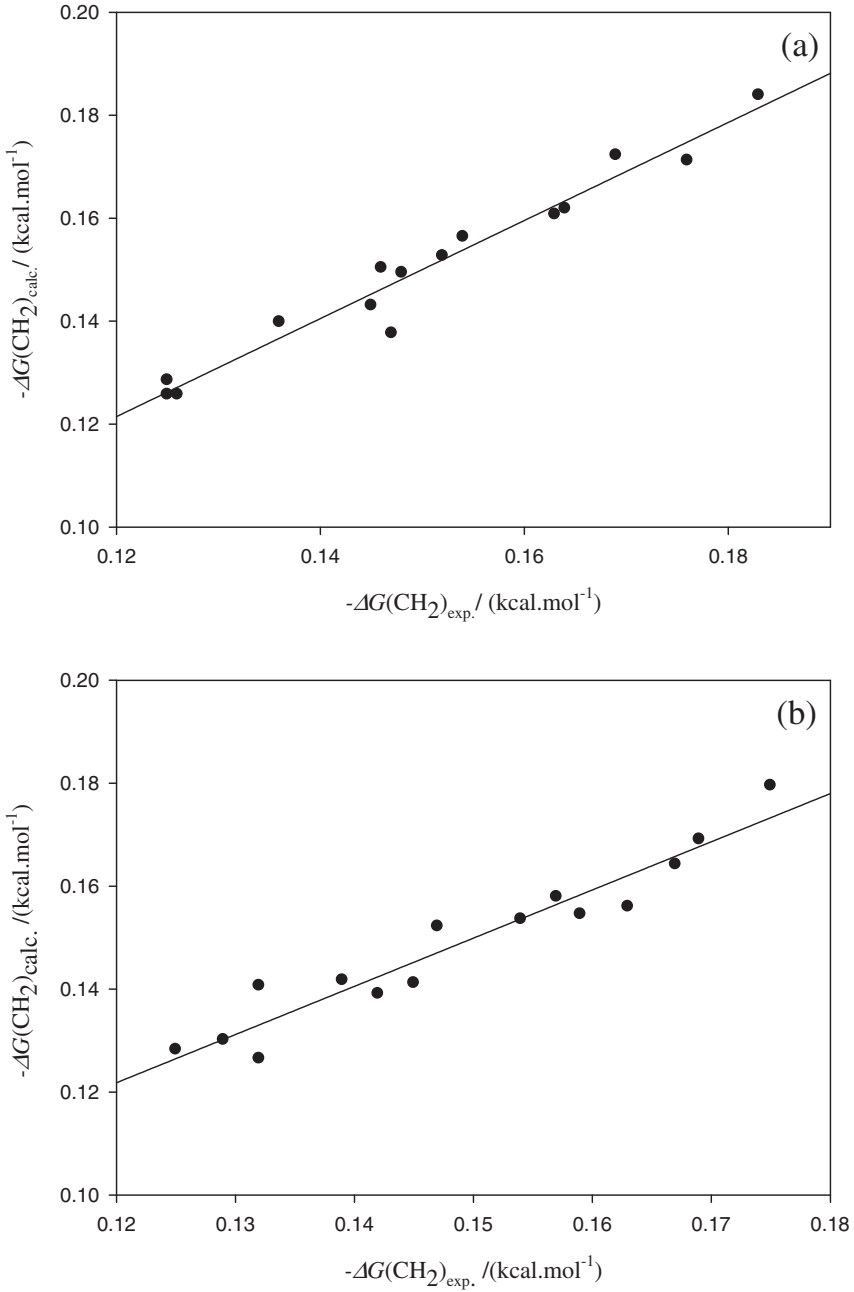

FIGURE 6. Comparison of experimental $\Delta G\left(\mathrm{CH}_{2}\right)$ values and calculated data based on equation ( 8 ) for $\mathrm{NaCl}$ and on equation (9) for $\mathrm{KCl}$, figures (a) and (b), respectively.

In the present work, two additive salts with a common anion were chosen. The cation $\mathrm{Na}^{+}$prove to be more effective changing the hydrophobicity of the phases and it provides higher slopes than the $\mathrm{K}^{+}$, which is in agreement with the Hofmeister series. Since ion $\left(\mathrm{Na}^{+}\right)$is more kosmotropic, it presents a higher salting-out ability.

The systems were prepared at the same $\mathrm{pH}$ and with increasing salt ionic strength $(I)$. Therefore, the feasibility of establishing a relationship between the relative hydrophobicity of the phases in a given TLL and the ionic strength of the salt additive was investigated. In figure 5 the $\Delta G\left(\mathrm{CH}_{2}\right)$ is plotted against the TLL and the I of the salt added. A simple correlation was found for each salt. For the systems with added $\mathrm{NaCl}$ salt the following correlation was found:

$$
\begin{aligned}
-\Delta G\left(\mathrm{CH}_{2}\right)= & (-0.036 \pm 0.011) I+(0.858 \pm 0.051) \mathrm{TLL} \\
& +(0.066 \pm 0.010) I^{2}+(-0.838 \pm 0.222) \mathrm{TLL}^{2}, \\
& N=15 ; r^{2}=0.959 .
\end{aligned}
$$

For the systems with added $\mathrm{KCl}$ salt the corresponding correlation is given by the expression:

$$
\begin{aligned}
-\Delta G\left(\mathrm{CH}_{2}\right)= & (0.906 \pm 0.055) \mathrm{TLL}+(0.027 \pm 0.003) I^{2} \\
& +(-1.111 \pm 0.256) \mathrm{TLL}^{2}, \quad N=15 ; r^{2}=0.959 .
\end{aligned}
$$

In figure 6 the calculated $\Delta G\left(\mathrm{CH}_{2}\right)$ (based on equations (8) and (9)) is plotted as function of the experimental $\Delta G\left(\mathrm{CH}_{2}\right)$ data and a good correlation was found (figure $6 \mathrm{a}$ and $\mathrm{b}$, for $\mathrm{NaCl}$ and $\mathrm{KCl}$ salts, respectively). 
It is known that $\Delta G\left(\mathrm{CH}_{2}\right)$ is not the single measure of the phase properties governing the partitioning of a solute in ATPS, however, when ATPSs is used for separation purposes, these results are of important utility for the improvement/achievement of a specific separation of biological solutes. The hydrophobic interactions between the solute and the phase forming components are one of the major responsible for the selective partition [9,11] therefore, optimal conditions for a target product can be predicted (e.g., increase of the relative hydrophobicity of the phases to promote the partition of the most hydrophobic solute to the most hydrophobic phase while the contaminants stay in the other phase).

\section{Conclusions}

The relative hydrophobicity of the equilibrium phases of (PEG $\left.8000+\mathrm{Na}_{2} \mathrm{SO}_{4}\right)$ ATPSs, all containing $0.01 \mathrm{~mol} \cdot \mathrm{L}^{-1} \mathrm{NaPB}, \mathrm{pH} 7.4$, and differing in composition, type and concentration of salt additive ( $\mathrm{NaCl}$ or $\mathrm{KCl}$ with concentration up to $1.0 \mathrm{~mol} \cdot \mathrm{L}^{-1}$ ) was studied by partitioning a series of five sodium salts of DNP-amino acids with aliphatic side chains in three different tie-lines of each biphasic system. It has been demonstrated that $\Delta G\left(\mathrm{CH}_{2}\right)$ can be used as a parameter characteristic of the each tie-line in a given ATPS and there is a linear relationship between the relative hydrophobicities of the TLL.

It is known that $\Delta G\left(\mathrm{CH}_{2}\right)$ cannot be used as a single measure of the solvent properties of the phases and therefore it cannot be used alone for comparison of the different ATPS, but this parameter it is very important for the physico-chemical characterization of the ATPS. The systems were characterized by phase diagrams (binodal curve and tie-lines) [23] and the free energy of transfer of a methylene group between the coexisting phases determined to obtain the difference between the hydrophobic character of the equilibrium phases.

The results obtained in this study will contribute for a better understanding of the mechanisms of solute distribution in these systems and will certainly provide new insight for applications in the biotechnological industry. The results shown that, these systems can be easily designed to achieve a specific separation.

\section{Acknowledgments}

Luisa A. Ferreira acknowledges the financial support (SFRH/ BPD/47607/2008) from Fundação para a Ciência e a Tecnologia (Lisboa, Portugal).

\section{References}

[1] P.G. Mazzola, A.M. Lopes, F.A. Hasmann, A.F. Jozala, T.C.V. Penna, P.O. Magalaes, C.O. Rangel-Yagui, A. Pessoa Jr., J. Chem. Technol. Biotechnol. 83 (2008) 143157.

[2] P.P. Madeira, C.A. Reis, A.E. Rodrigues, L.M. Mikheeva, B.Y. Zaslavsky, J. Phys Chem. B 114 (2010) 457-462.

[3] S.C. Silvério, O. Rodríguez, J.A. Teixeira, E.A. Macedo, J. Chem. Eng. Data 55 (2010) 1285-1288.

[4] S.C. Silvério, O. Rodríguez, J.A. Teixeira, E.A. Macedo, J. Chem. Thermodyn. 42 (2010) 1063-1069.

[5] A.M. Azevedo, P.A.J. Rosa, I.F. Ferreira, M.R. Aires-Barros, J. Biotechnol. 132 (2007) 209-217.

[6] J.G. Huddleston, H.D. Willauer, R.D. Rogers, J. Chem. Eng. Data 48 (2003) 12301236.

[7] P.A. Albertsson, Partition of Cell Particles and Macromolecules, third ed., Wiley, New York, 1986.

[8] B.Y. Zaslavsky, Aqueous Two-phase Partitioning: Physical Chemistry and Bioanalytical Applications, Marcel Dekker, New York, 1994.

[9] F. Hachem, B.A. Andrews, J.A. Asenjo, Enzyme Microb. Technol. 19 (1996) 507517.

[10] I.P. Trindade, M.M. Diogo, D.M.F. Prazeres, J.C. Marcos, J. Chromatogr. A 1082 (2005) 176-184.

[11] P.A.J. Rosa, A.M. Azevedo, M.R. Aires-Barros, J. Chromatogr. A 1141 (2007) 5060.

[12] P.A.J. Rosa, A.M. Azevedo, S. Sommerfeld, M. Mutter, M.R. Aires-Barros, W Bäcker, J. Biotechnol. 139 (2009) 306-313.

[13] A.M. Azevedo, A.G. Gomes, P.A.J. Rosa, I.F. Ferreira, A.M.M.O. Pisco, M.R. AiresBarros, Sep. Purif. Technol. 65 (2009) 14-21.

[14] B.Y. Zaslavsky, L.M. Miheeva, S.V. Rogozhin, J. Chromatogr. 216 (1981) $103-$ 113.

[15] B.Y. Zaslavsky, N.D. Gulaeva, S. Djafarov, E.A. Masimov, L.M. Miheeva, J. Colloid Interf. Sci. 137 (1990) 147-156.

[16] N. Gulyaeva, A. Zaslavsky, P. Lechner, A. Chait, B. Zaslavsky, J. Chromatogr. B 743 (2000) 187-194.

[17] O. Rodríguez, S.C. Silvério, P.P. Madeira, J.A. Teixeira, E.A. Macedo, Ind. Eng. Chem. Res. 46 (2007) 8199-8204.

[18] S.C. Silvério, P.P. Madeira, O. Rodríguez, J.A. Teixeira, E.A. Macedo, J. Chem. Eng. Data 53 (2008) 1622-1625.

[19] P.P. Madeira, J.A. Teixeira, E.A. Macedo, L.M. Mikheeva, B.Y. Zaslavsky, J Chromatogr. A 1185 (2008) 85-92.

[20] M.L. Moody, H.D. Willauer, S.T. Griffin, J.G. Huddleston, R.D. Rogers, Ind. Eng. Chem. Res. 44 (2005) 3749-3760.

[21] H.D. Willauer, J.G. Huddleston, R.D. Rogers, Ind. Eng. Chem. Res. 41 (2002) 1892-1904.

[22] H.D. Willauer, J.G. Huddleston, R.D. Rogers, Ind. Eng. Chem. Res. 41 (2002) 2591-2601.

[23] L.A. Ferreira, J.A. Teixeira, J. Chem. Eng. Data 56 (2011) 133-137.

[24] P.P. Madeira, J.A. Teixeira, E.A. Macedo, L.M. Mikheeva, B.Y. Zaslavsky, Fluid Phase Equilibr. 267 (2008) 150-157.

[25] J.G. Huddleston, H.D. Willauer, S.T. Griffin, R.D. Rogers, Ind. Eng. Chem. Res. 38 (1999) 2523-2539.

JCT 11-2 